completes a work which should undoubtedly find a place in the library of the British chemists and engineers who are now working on the many-sided problem of rendering Great Britain to some extent independent of foreign sources for her supplies of liquid fuels.

C. H. L

\section{Botanical Text-books.}

(I) A Class Book of Botany. By Ernest Stenhouse. Pp. xi + 514. (London: Macmillan and Co., Ltd., I925.) $7 s .6 d$.

(2) A Textbook of General Botany. By Prof. William H. Brown. Pp. xi +484 . (Boston, New York and London: Ginn and Co., I925.) I3s. 6d. net.

HE large variety of text-books of botany which
have been published during the last few years, in Great Britain and in America, render it difficult for any addition to their number to present novelty of either treatment or subject matter. Most such works tend towards one of two extremes according as they appear to aim, on one hand, at imparting the maximum number of facts in the minimum of space, which in the hands of the inexperienced writer may lead to the endeavour to include all aspects of the subject, even perhaps insecurely founded hypotheses; or, on the other hand, the author may emphasise the more philosophical aspects of the subject, sometimes even to the exclusion of essential data. The best textbooks are those which most nearly attain the balanced combination of these two aspects, and whilst subordinating facts to the illustration of principles, nevertheless provide the student with such a foundation of knowledge as shall enable him to build securely the superstructure of his later studies. It is in the selection of the illustrative data and its manner of presentation as part of a co-ordinated concept of vegetable life that the student gains by the experience of the author, provided that the latter has not forgotten with the passage of time the rungs on which he slipped as he himself climbed the ladder of progress.

The two books under review illustrate the two tendencies indicated above. In the "Class Book of Botany," by Mr. Stenhouse, we are impressed by the large amount of information which it contains, especially since it is intended for the use of those preparing for matriculation and similar junior examinations. But the facts are somewhat insistent as such, their significance and co-ordination too little emphasised. A useful feature is that each of the numerous chapters is preceded by suggestions for practical work, including many of an experimental character. Also each chapter is followed by a number of questions from examination papers.

NO. 2920, VOL. I I 6]
There is much that is admirable in Mr. Stenhouse's book, but we have an ever-present consciousness as we peruse its pages that we are preparing for an examination. That it may produce successful candidates is very probable, but whether it will create lovers of the subject for its own sake is less certain. There are numerous illustrations of which the line drawings are in many cases reproductions of well-known figures, whilst the half-tone blocks have mostly been prepared from Mr. Irving's excellent plant studies. The latter are indeed the chief redeeming feature of an otherwise uninspiring chapter on common British trees. It may be noted that, apart from the ground usually covered by text-books of an elementary character, the simpler microscopic structure of plants is described, and there is a short account of a few of the common types of plant community.

(2) Prof. Brown's "Textbook of General Botany" is likewise of an elementary character and covers much the same ground. The earlier chapters treat of the various regions of the plant considered from the structural and physiological points of view, whilst the later chapters are devoted to the subdivisions of the vegetable kingdom, heredity, geographical distribution, etc.

Here the treatment is much more general in character, and occasionally one feels that the author passes too lightly over the ground, but the spirit in which the book is written is well expressed by the author's statement in the introductory chapter that " all persons should have some knowledge of botany if only for the purpose of understanding better so important a part of their environment as the vegetable kingdom." The text is well illustrated with more than five hundred original figures, mostly taken from tropical or subtropical material, the utility of which, however, is somewhat discounted by the lack of annotation.

The text in both of these works is divided into headed paragraphs: a device which, if it has advantages, tempts towards a discontinuity of narrative that neither author has been able to resist.

E. J.S.

\section{Bird Islands of Peru.}

Bird Islands of Peru: the Record of a Sojourn on the West Coast. By Robert Cushman Murphy. Pp. xx $+362+32$ plates. (New York and London: G. P. Putnam's Sons, Ltd., r925.) ' 5 ss. net.

THE western coast of South America is washed throughout a large part of its extent by a great river of cold water, an arm of the Pacific Antarctic drift. This, the Humboldt Current, has effects upon climate, vegetation, fauna, and human affairs that are no less profound than those of the Atlantic Current in 